\title{
The PPARy agonist, rosiglitazone, attenuates airway inflammation and remodeling via heme oxygenase-1 in murine model of asthma
}

Jing XU, Yan-ting ZHU, Gui-zuo WANG, Dong HAN, Yuan-yuan WU, De-xin ZHANG, Yun LIU, Yong-hong ZHANG, Xin-ming XIE, Shao-jun LI, Jia-mei LU, Lu LIU, Wei FENG, Xiu-zhen SUN, Man-xiang LI*

Department of Respiratory Medicine, the Second Affiliated Hospital of Xi'an Jiaotong University, Xi'an, Shanxi 710004, China

Aim: Rosiglitazone is one of the specific PPARy agonists showing potential therapeutic effects in asthma. Though PPARy activation was considered protective in inhibiting airway inflammation and remodeling in asthma, the specific mechanisms are still unclear. This study was aimed to investigate whether heme oxygenase-1 (HO-1) related pathways were involved in rosiglitazone-activated PPARy signaling in asthma treatment.

Methods: Asthma was induced in mice by multiple exposures to ovalbumin (OVA) in 8 weeks. Prior to every OVA challenge, the mice received rosiglitazone $(5 \mathrm{mg} / \mathrm{kg}, \mathrm{po})$. After the mice were sacrificed, the bronchoalveolar lavage fluid (BALF), blood samples and lungs were collected for analyses. The activities of HO-1, MMP-2 and MMP-9 in airway tissue were assessed, and the expression of PPARY, HO-1 and p21 proteins was also examined.

Results: Rosiglitazone administration significantly attenuated airway inflammation and remodeling in mice with OVA-induced asthma, which were evidenced by decreased counts of total cells, eosinophils and neutrophils, and decreased levels of IL-5 and IL-13 in BALF, and by decreased airway smooth muscle layer thickness and reduced airway collagen deposition. Furthermore, rosiglitazone administration significantly increased PPARy, HO-1 and p21 expression and HO-1 activity, decreased MMP-2 and MMP-9 activities in airway tissue. All the therapeutic effects of rosiglitazone were significantly impaired by co-administration of the HO-1 inhibitor ZnPP. Conclusion: Rosiglitazone effectively attenuates airway inflammation and remodeling in OVA-induced asthma of mice by activating PPARY/HO-1 signaling pathway.

Keywords: asthma; OVA-induced asthma; PPARy; rosiglitazone; HO-1; p21; MMP-2; MMP-9; ZnPP

Acta Pharmacologica Sinica (2015) 36: 171-178; doi: 10.1038/aps.2014.128; published online 26 Jan 2015

\section{Introduction}

Resulted from activation of inflammatory cells including eosinophils, neutrophils, macrophages, mast cells, and T lymphocytes, asthma is now generally accepted as a chronic airway inflammatory disorder ${ }^{[1]}$. Under pathological condition of asthma, inflammatory mediators such as cytokines and chemokines, would be released from these cells to induce sustained chronic airway inflammation which eventually leads to bronchoconstriction and airway remodeling ${ }^{[2]}$. Stimulated by chronic inflammation, elevated smooth muscle cell proliferation and extracellular matrix (ECM) deposition ${ }^{[3,4]}$ would lead to alteration of molecular constitute composition and reorganization of airway wall structure which are the characteristics of airway remodeling ${ }^{[5]}$. Furthermore, previous studies sug-

\footnotetext{
* To whom correspondence should be addressed.

E-mail manxiangli@hotmail.com

Received 2014-06-29 Accepted 2014-11-07
}

gested airway remodeling is one of the risk factors for corticosteroid-refractory (CSR) asthma ${ }^{[6,7]}$. Thus, drugs and reagents which could suppress airway inflammation and remodeling are of therapeutic significance.

Peroxisome proliferator-activated receptors (PPARs) belong to the ligand-activated nuclear receptor superfamily. Three isoforms of PPAR have been cloned, namely the PPAR-alpha (PPARa), PPAR gamma (PPAR $\gamma$ ), and PPAR-delta (PPARס) ${ }^{[8]}$. Distributed in different organs and tissues, these receptors play important roles in critical biological processes including glucose and lipid homeostasis regulation, cell proliferation, cell differentiation and inflammation ${ }^{[9]}$. Strategy of activating PPARY has shown benefits in protecting cell from inflammation-induced injuries. Rosiglitazone was identified as one of the specific agonists of PPARY which exerted potential therapeutic effects on acute lung injury and pulmonary arterial hypertension according to previous studies of our group ${ }^{[10,11]}$. A study suggested that rosiglitazone prevented perinatal 
nicotine exposure- induced asthma in rat offspring ${ }^{[12]}$. It was reasonable for us to presume that rosiglitazone could alleviate airway remodeling by activating PPARY in asthma.

According to previous literatures, heme oxygenase (HO)-1 was suggested as one of the down-stream effectors of PPAR $\gamma^{[11,13]}$. Our previous work showed that HO-1 could upregulate expression of p21 protein ${ }^{[10]}$ which was considered as an inhibitor of cell proliferation. Notably, matrix metalloproteinase (MMP)2 and MMP-9 were considered regulated by HO-1, which are the key molecules adjusting ECM deposition and degradation in airway remodeling. Thus, PPARY/HO-1/ MMPs and PPAR $/ \mathrm{HO}-1 / \mathrm{p} 21$ are the possible pathways in regulating airway remodeling in asthma. In this study, in vivo model of asthma induced by ovalbumin (OVA) administration was used to evaluate the therapeutic effects of rosiglitazone. Furthermore, the possible involvement of PPARY/HO-1/ MMPs and PPARY/HO-1/p21 pathways in rosiglitazone's anti-asthma mechanism was also investigated.

\section{Materials and methods}

\section{Animals and in vivo asthma model}

Thirty-two female Balb/c mice (6 week-old, SPF class, provided by Experimental Animal Center of Xi'an Jiaotong University) were maintained in separated cages under controlled condition (temperature $25 \pm 1.5^{\circ} \mathrm{C}$, humidity $65 \% \pm 4 \%, 12-\mathrm{h}$ light- dark artificial cycle) for $7 \mathrm{~d}$ prior to subsequent experiments. Mice could access freely to fresh water and standard diet continuously. The animal experimental procedures followed protocols approved by Medical Animal Research Ethics Committee at $\mathrm{Xi}^{\prime}$ an Jiaotong University.

Thirty-two mice were divided into 4 groups evenly and randomly: control group (Con), OVA-induced asthma group (OVA), rosiglitazone treated OVA-induced asthma group (OVA+ROSI) and rosiglitazone and zinc protoporphyrin-IX (ZnPP) treated OVA-induced asthma group $(\mathrm{OVA}+\mathrm{ROSI}+\mathrm{ZnPP})$. For in vivo asthma modeling, mice were initially sensitized by intraperitoneal injection of $0.1 \mathrm{~mL}$ PBS supplemented with $25 \mu \mathrm{g}$ OVA (Sigma-Aldrich) and $500 \mu \mathrm{g}$ alum (Sigma-Aldrich) at d 1, 7, and 14. Then in the following 8 weeks, OVA (15 $\mu \mathrm{g})$ was administered intranasally 3 days per week. For rosiglitazone treatment, rosiglitazone (GSK, $5 \mathrm{mg} / \mathrm{kg}$ ) was administered orally $6 \mathrm{~h}$ prior to every OVA intranasal challenge ${ }^{[14]}$. For ZnPP treatment, ZnPP (SigmaAldrich, $10 \mathrm{mg} / \mathrm{kg}$, dissolved in $5 \mathrm{mmol} / \mathrm{L} \mathrm{NaOH}, \mathrm{pH}=7.4$ ) was administered intraperitoneally accompanied with every rosiglitazone treatment.

\section{Serum and bronchoalveolar lavage fluid (BALF) collection}

After mice were sacrificed by overdose anaesthetization of pentobarbital sodium (100 mg/kg), blood sample was collected. Serum was collected after blood was centrifuged at $1200 \times g$ for $15 \mathrm{~min}$ at room temperature which was then stored at $-80^{\circ} \mathrm{C}$. Cold sterile PBS was used to perform bronchoalveolar lavage (BAL) by intratracheal injection. Then the PBS was collected as BALF and the average fluid recovery rate was greater than $90 \%$. BALF was centrifuged at $800 \times g$ for $10 \mathrm{~min}$ at $4{ }^{\circ} \mathrm{C}$. The resulted pellet cells were subjected to differential cell count after Wright Giemsa staining. Total cell, eosinophils and neutrophils were counted under a light microscope. The result supernatant was stored at $-80^{\circ} \mathrm{C}$ for subsequent enzymelinked immunosorbent assay (ELISA).

\section{Histological assessment}

Immediately after the mice were sacrificed, the right lung was lavaged by fixation solution $(0.8 \%$ formalin and $4 \%$ acetic acid) intratracheally. After harvested, lung was further fixed by $10 \%(v / v)$ neutral buffered formalin for $48 \mathrm{~h}$ and then embedded with paraffin. The lung was then sliced into sections $(4 \mu \mathrm{m})$ which were then processed by hematoxylin \& eosin (H\&E) staining and Masson staining. Spot Colled Color Digital camera ( $Q$ Imaging) was used to observe the sections and capture the photomicrograph images. The airway smooth muscle layer thickness and collagen intensities were measured by Un-ScanIt software.

\section{ELISA assay}

Mice IL-5 ELISA kit (R\&D) and mice IL-13 ELISA kit (R\&D) were used to detect IL-5 and IL-13 concentrations in BALF supernatant. In addition, serum OVA-sIgE level was detected by using mice OVA-sIgE ELISA kit (R\&D). Experimental protocols were in accordance with manufacturer's instructions.

\section{Western blotting}

Harvested left lungs were minced and then homogenized by RIPA lysis buffer (Sigma-Aldrich) supplemented with phosphatase inhibitor and protease inhibitor cocktail on ice. After lysates were centrifuged at $14000 \times g$ for $20 \mathrm{~min}$ at $4^{\circ} \mathrm{C}$, the resulted supernatant was collected as total protein. A BCA Protein Assay kit (Thermo) was used to determine the concentration of protein sample. Protein $(50 \mu \mathrm{g})$ was loaded and then separated by vertical electrophoresis on SDS-PAGE gel. The separated protein was transferred electronically to Trans-Blot nitrocellulose membrane (Bio-Rad) which were then incubated with antibodies against PPARY (Abcam), HO-1 (Cell Signaling Tech), p21 (BD Pharmingen), and $\beta$-Actin (Abcam). After washing, the membranes were incubated with corresponding horseradish peroxidase-conjungated secondary antibodies (Sigma-Aldrich). Finally, the membranes were developed by SuperSignal West Pico Chemiluminescent Substrate (Pierce Protein Biology) and exposed to X-ray films. The intensities of the immunoblots were quantified by Scion Image software.

\section{HO-1 enzymatic activity assay}

The tissue homogenates was centrifuged at $10000 \times g$ for 15 min at $4{ }^{\circ} \mathrm{C}$. The resulted supernatant was treated as testing sample. The enzymatic activity of HO-1 was evaluated by using HO-1 activity assay kit (GenMed) according to the manufacturer's instructions. This spectrophotometric method was based on the conversion of heme into carbon monoxide, biliverdin and ferrous iron. 
MMP activity determination by zymography

The extracted protein from lung tissue was mixed with Trisglycine SDS sample buffer without reducing agents and separated in gelatin zymography gel by vertical electrophoresis. Then the gel was incubated in $2.5 \%$ Triton $X-100$ for $30 \mathrm{~min}$, followed by incubation in Tris- $\mathrm{HCl}(10 \mathrm{mmol} / \mathrm{L}, \mathrm{pH}=7.4)$ supplemented with $0.2 \mathrm{~mol} / \mathrm{L} \mathrm{NaCl}, 5 \mathrm{mmol} / \mathrm{L} \mathrm{CaCl}_{2}$ and $0.02 \%$ Brij 35. $0.5 \%$ Coomassie blue R250 was used to stain the gel which was destained in destaining buffer (containing 25\% $\mathrm{MeOH}$ and $10 \%$ acetic acid). The resulted bands were visualized and analyzed by Gel DocTM XR (Bio-Rad).

\section{Statistics}

Values in this study are presented in a (mean \pm SD) manner. Data was analyzed by SPSS (SPSS, ver 16.0) statistic software. Differences were analyzed using one-way ANOVA followed by Tukey's post-hoc tests. $P<0.05$ was considered statistically significant.

\section{Results}

Rosiglitazone treatment attenuated airway inflammation in OVAinduced asthma model

Both of eosinophils cell count and inflammatory cytokine detection were used to investigate the effects of rosiglitazone in asthma mice. The cell count of total cell, eosinophils and neutrophils elevated dramatically in OVA compared with Con in BALF. Eosinophils increase is generally considered as the hall mark of asthma onset and neutrophils is considered the indicator of inflammation (Figure 1). Rosiglitazone administration in ROSI significantly reduced inflammatory cell accu- mulation in BALF. Moreover, also demonstrated in Figure 1, levels of inflammatory cytokines including IL-5, IL-13, and OVA-sIgE increased significantly in OVA-induced asthma mice which were reduced by ROSI significantly. Notably, ZnPP administration dramatically impaired rosiglitazone's inhibitory effects on eosinophils accumulation and inflammatory cytokine elevation.

\section{Rosiglitazone treatment alleviated airway remodeling in OVA-} induced asthma model

Collagen deposition and airway smooth muscle layer thickness were investigated by H\&E and Masson's staining, respectively to indicate the degree of airway remodeling. Figure 2 demonstrated the captured images of H\&E and Masson's staining of airway tissue. Collagen deposition and airway smooth muscle layer thickness were significantly increased in OVA-treated mice but then alleviated remarkably by rosiglitazone treatment. However, in OVA+ROSI+ZnPP, after administration of $\mathrm{ZnPP}$, the HO-1 inhibitor, collagen deposition and airway smooth muscle layer thickness were more increased than in OVA+ROSI group.

The effects of rosiglitazone and ZnPP on PPARy expression in asthma mice

As shown in Figure 3, the expression level of PPARY was significantly increased in OVA than Con. In OVA+ROSI, further elevated PPARY expression was found when compared with OVA. Furthermore, there were no significant changes of PPAR $\gamma$ expression after $\mathrm{ZnPP}$ administration in $\mathrm{OVA}+\mathrm{ROSI}+\mathrm{ZnPP}$ in comparison to OVA+ROSI group.
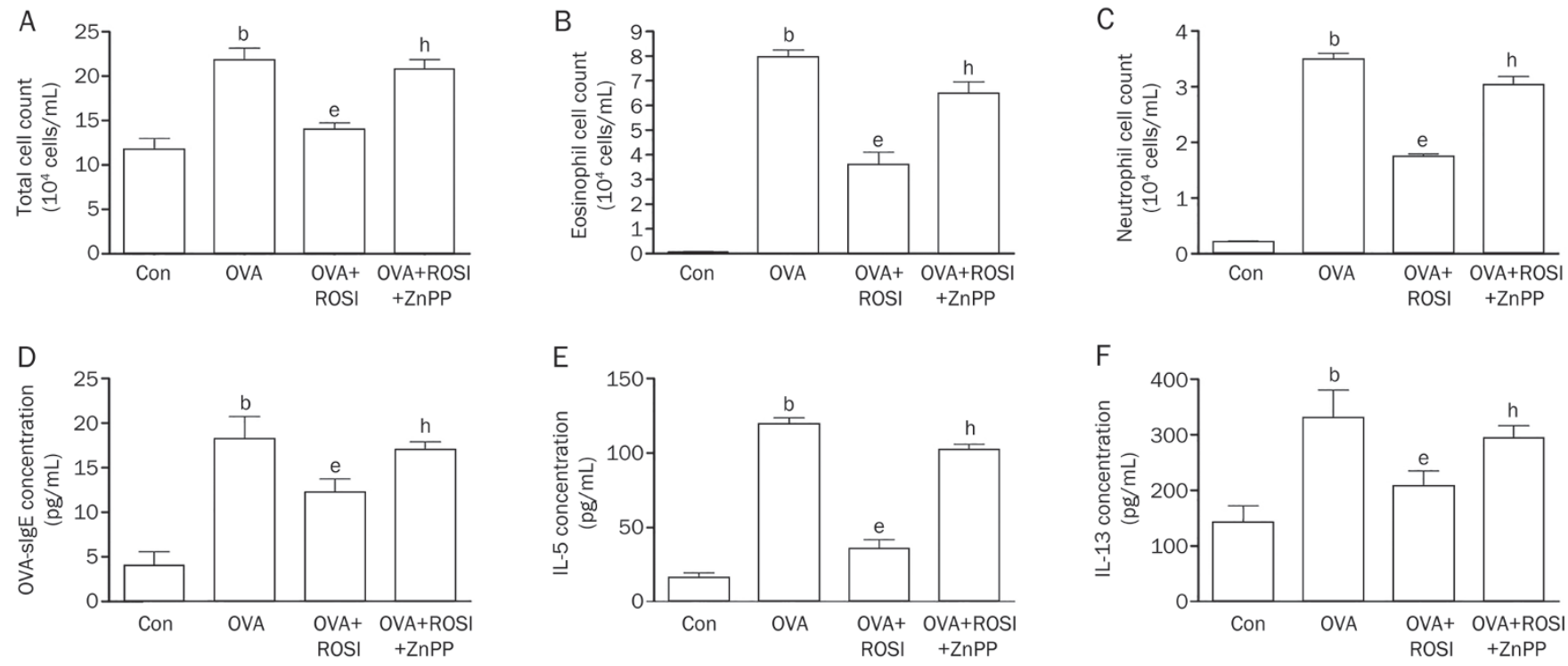

Figure 1. Columns indicate total cell count (A), eosinophil cell count (B) and neutrophil cell count (C) in every $10^{4}$ cells/mL. (D) Columns indicate the serum OVA-sIgE concentration in Con, OVA, OVA+ROSI, and OVA+ROSI+ZnPP respectively. (E and F) columns indicate the IL-5 and IL-13 concentrations detected in BALF in Con, OVA, OVA+ROSI, and OVA+ROSI+ZnPP respectively. Values are presented in (mean \pm SD) manner in column

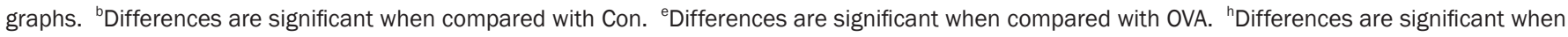
compared with OVA+ROSI. 

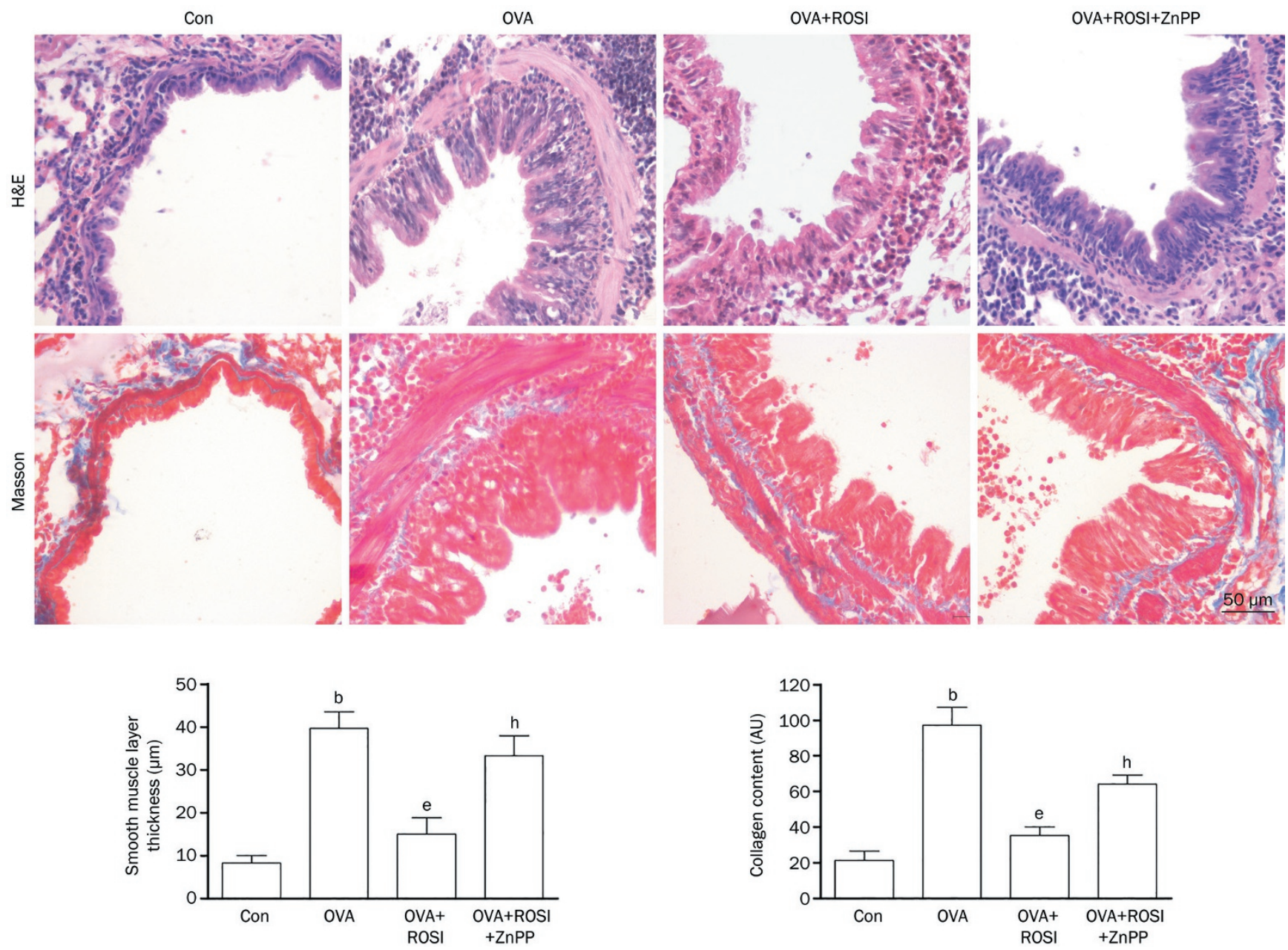

Figure 2. The upper panel of this figure demonstrated H\&E and Masson's staining of airway tissue slice from Con, OVA, OVA+ROSI, and OVA+ROSI+ZnPP, respectively. On the lower panel, columns on the left part indicate the measured smooth muscle layer thickness by observing $\mathrm{H} \& \mathrm{E}$ stained slices in Con, OVA, OVA+ROSI, and OVA+ROSI+ZnPP, respectively; columns on the right part indicate the measured collagen content by observing Masson stained slices in Con, OVA, OVA+ROSI, and OVA+ROSI+ZnPP, respectively. Values are presented in (mean \pm SD) manner in column graphs. ${ }^{\mathrm{b} P}<0.05$ vs Con. ${ }^{\mathrm{e}} \mathrm{P}<0.05$ vs OVA. ${ }^{\mathrm{h}} \mathrm{P}<0.05$ vs OVA+ROSI.

The effects of rosiglitazone and ZnPP on HO-1 enzymatic activity and expression

Figure 4 demonstrated HO-1 enzymatic activity and expression level determined by spectrophotometric method and Western blotting respectively in each group. It was found that the HO-1 enzymatic activity was up-regulated in OVA treated mice. In OVA+ROSI, the enzymatic activity was augmented after rosiglitazone administration. As the HO-1 inhibitor, $\mathrm{ZnPP}$ treatment dramatically reduced HO-1 enzymatic activity. Also demonstrated in Figure 4, the expression level of HO-1 increased in OVA-treated mice and further increased in mice received co-administration of OVA and rosiglitazone. However, in OVA+ROSI+ZnPP, ZnPP treatment significantly reduced $\mathrm{HO}-1$ expression.

The effects of rosiglitazone and ZnPP on expressions of p21 and MMPs

As the down- stream effectors of HO-1 which participate in airway remodeling, expression of p21 and activities of MMP-2 and MMP-9 were also examined in this study. Figure 5A demonstrated the expression level of p21 in each group. We found that p21 expression was down-regulated in mice with asthma. However, after administration of rosiglitazone in OVA+ROSI, the p21 expression was significantly up-regulated. ZnPP treatment dramatically reduced p21 expression in OVA+ROSI+ZnPP than OVA+ROSI. Figure 5B demonstrated activities of MMP-2 and MMP-9 detected by zymography. The up-regulated MMP-2 and MMP-9 activities in OVA were impaired by rosiglitazone treatment in OVA+ROSI. Nevertheless, the MMP-2 and MMP-9 activities were elevated after $\mathrm{ZnPP}$ administration in OVA+ROSI+ZnPP.

\section{Discussion}

Asthma is a common chronic airway inflammatory disorder due to immune and inflammatory reactions. Airway inflammation and remodeling are the two characterized pathological 

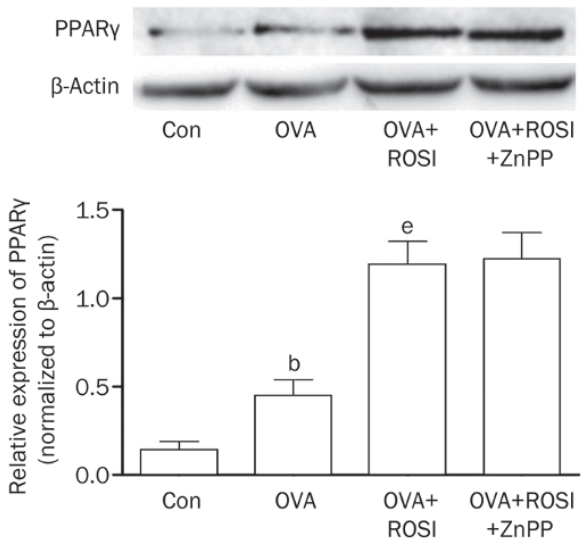

Figure 3. The upper part of this figure demonstrated the immunoblots of PPARy and $\beta$-actin (as internal reference) in airway tissue in Con, OVA, OVA+ROSI, and OVA+ROSI+ZnPP, respectively. Columns on the lower part of this figure indicate relative expression levels of PPARy in Con, OVA, OVA+ROSI, and OVA+ROSI+ZnPP, respectively. Values are presented in (mean \pm SD) manner in column graphs. ${ }^{\text {b } P<0.05 ~ v s ~ C o n . ~}{ }^{e} P<0.05$ vs OVA.
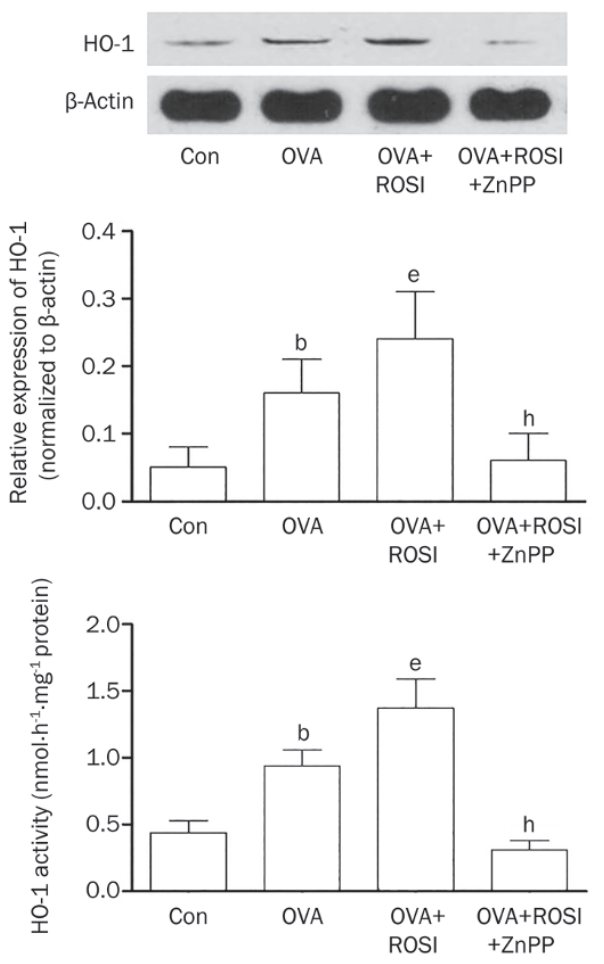

Figure 4. The upper part of this figure demonstrated the immunoblots of $\mathrm{HO}-1$ and $\beta$-actin (as internal reference) in airway tissue in Con, OVA, $O V A+R O S I$, and OVA+ROSI+ZnPP, respectively. On the lower panel, columns on the middle part indicate the relative expression of HO-1 in Con, OVA, OVA+ROSI, and OVA+ROSI+ZnPP, respectively; columns on the bottom part indicate the detected HO-1 enzymatic activity in Con, OVA, OVA+ROSI, and OVA+ROSI+ZnPP, respectively. Values are presented in (mean \pm SD) manner in column graphs. ${ }^{b} P<0.05$ vs Con. ${ }^{e} P<0.05$ vs OVA. ${ }^{\mathrm{h}} \mathrm{P}<0.05$ vs OVA+ROSI. features of asthma ${ }^{[15,16]}$. Among the inflammatory cells participated in occurrence and development of asthma, eosinophils play a featured role ${ }^{[17,18]}$. It was considered that the inflammatory mediators and cytokines released by accumulated eosinophils in airway resulted in mucus hypersecretion, increased vascular permeability, bronchial hyperresponsiveness, smooth muscle contraction ${ }^{[19,20]}$. Furthermore, cytokines and growth factors released by inflammatory cells such as neutrophils are also involved in initiation of airway remodeling which is characterized by airway smooth muscle proliferation ${ }^{[21]}$. In this study, we investigated the therapeutic effect of rosiglitazone in OVA-induced asthma and possible mechanisms involved. We found that rosiglitazone attenuated both airway inflammation and remodeling. The results in this study suggested the therapeutic effects were correlated with activation of PPARY/ HO-1 pathway.

It is believed that PPARY is a nuclear factor with broad functions in regulating various critical cellular biological processes. PPARY was originally known as the mediator in regulating cell differentiation and lipid metabolism in adipocytes ${ }^{[2]}$. However, subsequent accumulating evidence indicated PPAR $\gamma^{\prime} \mathrm{s}$ more extensive functions in regulating cell cycle, apoptosis, inflammation, proliferation and so on ${ }^{[23]}$. In this study, we found that PPARY expression was elevated in OVA- induced asthmatic animal. This finding was in accordance with results from previous study in which up-regulated PPARY expression was also found in human asthmatic airway ${ }^{[24]}$. Previous studies suggested that PPARY activation alleviated asthmatic features which was evidenced by decreased expressions of cytokines, reduced bronchoconstriction and impaired eosinophils accumulation ${ }^{[25,26]}$. Rosiglitazone, one of thiazolidinediones, which is generally considered an agonist for PPAR $\gamma$ with high affinity, was administered to asthmatic animals in this study. Though thiazolidinediones have been withdrawn from the clinical usage in diabetes because of the possible occurrence of cardiovascular complications, they are still of research value because of their property of activating PPARY. We found that rosiglitazone administration attenuated asthmatic features including airway eosinophils accumulation, inflammatory cytockine levels, smooth muscle layer thickness and collagen deposition, suggesting that the therapeutic effect against asthma exerted by rosiglitazone was associated with activation of PPARY and its down-stream pathways.

HO-1 is the inducible isoform of $\mathrm{HO}$ which catalyzes the degradation of heme into biliverdin, ferrous ion and carbon monoxide ${ }^{[27]}$. The enzymatic activity of HO-1 is often stimulated in responses to multiple stimuli such as UV radiation, lipopolysaccharide (LPS), heat shock and heavy metals ${ }^{[28]}$. Increased HO-1 activity is found protective against inflammation, excessive cell proliferation and interstitial fibrosis ${ }^{[29]}$. Previous study suggested HO-1 could protect against airway inflammation by down-regulating tumor necrosis factor receptor (TNFR) 1 dependent oxidative stress ${ }^{[30]}$. In asthma particularly, it was considered that the increase of HO-1 expression and activity were protective ${ }^{[31]}$. The anti-asthmatic effects of 
A
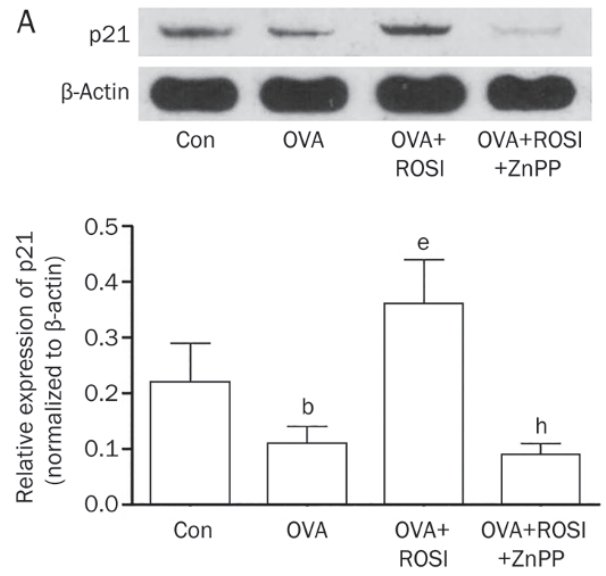

B
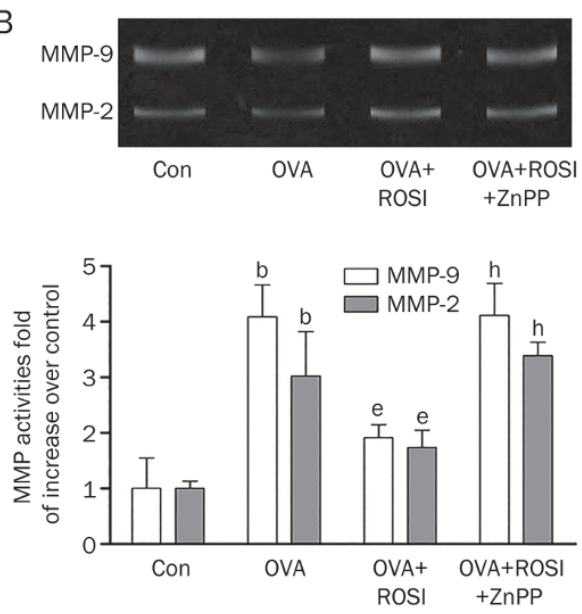

Figure 5. (A) On the upper panel, the immunoblots of p21 and $\beta$-actin (as internal reference) in Con, OVA, OVA+ROSI, and OVA+ROSI+ZnPP were demonstrated. Columns on the lower panel indicate the relative expression levels of p21 in Con, OVA, OVA+ROSI, and OVA+ROSI+ZnPP respectively. (B) The upper panel of this figure shows the blots of MMP9 and MMP-2 in gelatin zymography assay. Columns on the lower part indicate the activities of MMP-2 and MMP-9 in Con, OVA, OVA+ROSI, and OVA+ROSI+ZnPP, respectively. Values are presented in (mean $\pm S D$ ) manner in column graphs. ${ }^{b} P<0.05$ vs Con. ${ }^{e} P<0.05$ vs OVA. ${ }^{\text {h}} P<0.05$ vs OVA+ROSI.

several reagents and drugs such as Sanguisorba officinalis $L$ and Ulmus davidiana var japonica were also found associated with up-regulating airway $\mathrm{HO}-1^{[32,33]}$. HO-1 has been identified as the down-stream effectors of PPAR $\gamma$. In our previous studies, we found activation of PPARY by rosiglitazone significantly inhibited proliferation of pulmonary artery smooth muscle cells which was associated with induction of $\mathrm{HO}-1^{[10,11]}$. In the present study, HO-1 enzymatic activity was found increased in response to OVA administration, which was found further elevated in rosiglitazone treated asthmatic mice. After treated by HO-1 inhibitor ZnPP, however, HO-1 activity was reduced dramatically but $\mathrm{ZnPP}$ did not affect the PPARy expression in return. These results suggested that HO-1 was a key mediator in conducting PPARY signaling to exert protective and therapeutic effect in OVA-induced asthma. We also investigated the translational expression level of HO-1. The results turned out that HO-1 expression was increased in OVA-induced asthmatic mice and further increased by rosiglitazone treatment. Notably, the ZnPP treatment reduced HO-1 expression. There was an inducing effect of $\mathrm{ZnPP}$ on expression of $\mathrm{HO}-1$ via early growth response-1 (Egr-1) protein consensus sequence ${ }^{[34]}$. However, several other studies suggested ZnPP treatment reduced $\mathrm{HO}-1$ protein expression under certain stressful conditions which was in accordance with our results ${ }^{[35,36]}$. Indeed, there are conflicting results and arguments about the role of $\mathrm{ZnPP}$ in regulating $\mathrm{HO}-1$ expression and the related mechanisms are complicated. We presume it is possible that the effect of $\mathrm{ZnPP}$ on HO-1 expression differs under different pathological conditions and further studies are needed.

Several studies showed that this anti-proliferation effect of HO-1 was correlated with up-regulation of its downstream molecule $\mathrm{p} 21^{[37]}$ which was believed with proliferation inhibitory effect ${ }^{[38]}$. Results in this study indicated that after PPARY/HO-1 pathway was activated by rosiglitazone treatment in asthmatic mice, p21 expression was correspondingly increased. As a result, airway smooth muscle layer thickness which indicated the smooth muscle proliferation was reduced remarkably. In order to reinforce our finding, after the HO-1 activity was inhibited by $\mathrm{ZnPP}$, p21 expression was also inhibited which was accompanied by effect of impaired rosiglitazone on reducing airway smooth muscle layer thickness. Airway collagen deposition was considered as another feature of airway remodeling, particularly in the patients with chronic asthma ${ }^{[39-41]}$. Decreased activities of MMPs were believed associated with collagen deposition because MMPs are capable of degrading extracellular matrix components including collagen ${ }^{[42]}$. HO-1 was reported to reduce collagen by decreasing MMP-2/9 activities and increasing tissue inhibitors of metalloproteinase (TIMP) activities ${ }^{[43]}$. In this study, we found rosiglitazone-activated PPAR $/ \mathrm{HO}-1$ pathway reduced activities of MMP-2 and MMP-9 and collagen deposition in asthmatic airway, which was reversed by ZnPP administration. These results demonstrated above suggested that p21 and MMP-2/9 were responsible for rosiglitazone-activated PPAR $/ \mathrm{HO}-1$ pathway in reducing airway remodeling in asthmatic mice.

In summary, rosiglitazone showed therapeutic effect by attenuating airway inflammation and remodeling in mice with OVA-induced asthma. Activation of PPAR $\gamma / \mathrm{HO}-1 / \mathrm{p} 21$ and PPAR $/$ HO-1/MMPs pathways are involved in attenuated airway remodeling by rosiglitzone in mice with OVA-induced asthma.

\section{Acknowledgements}

This work was supported by National Natural Science Foundation of China (№ 81170051 and 81330002).

\section{Author contribution}

Jing XU, Xiu-zhen SUN, Yuan LIU, Yun LIU, and Man-xiang $\mathrm{LI}$ contributed to the research design; Jing XU performed the experiments and the data analysis with the assistance of Guizuo WANG, Yan-ting ZHU, Dong HAN, De-xin ZHANG, Jia- 
mei LU, Yong-hong ZHANG, Yuan-yuan WU, Xin-ming XIE, Shao-jun LI, Rui KE, Lu LIU, and Wei FENG; Jing XU, Xiuzhen SUN, and Man-xiang LI contributed to the writing of the manuscript.

\section{References}

1 Erjefalt JS. The airway epithelium as regulator of inflammation patterns in asthma. Clin Respir J 2010; 4 Suppl 1: 9-14.

2 Hoshino M. Airway inflammation and remodeling in bronchial asthma. Nihon Naika Gakkai Zasshi 2006; 95: 1425-30.

3 Elias JA, Zhu Z, Chupp G, Homer RJ. Airway remodeling in asthma. J Clin Invest 1999; 104: 1001-6.

4 Black JL, Roth M, Lee J, Carlin S, Johnson PR. Mechanisms of airway remodeling. Airway smooth muscle. Am J Respir Crit Care Med 2001; 164 (10 Pt 2): S63-6.

5 Vignola AM, Mirabella F, Costanzo G, Di Giorgi R, Gjomarkaj M, Bellia V, et al. Airway remodeling in asthma. Chest 2003; 123 (3 Suppl): 417S-22S.

6 Holgate ST, Polosa R. The mechanisms, diagnosis, and management of severe asthma in adults. Lancet 2006; 368: 780-93.

7 Holgate ST, Davies DE, Puddicombe S, Richter A, Lackie P, Lordan J, et al. Mechanisms of airway epithelial damage: epithelial-mesenchymal interactions in the pathogenesis of asthma. Eur Respir J Suppl 2003; 44: $24 s-29 s$.

8 Kota BP, Huang TH, Roufogalis BD. An overview on biological mechanisms of PPARs. Pharmacol Res 2005; 51: 85-94.

9 Lamers C, Schubert-Zsilavecz M, Merk D. Therapeutic modulators of peroxisome proliferator-activated receptors (PPAR): a patent review (2008-present). Expert Opin Ther Pat 2012; 22: 803-41.

10 Zhang D, Wang G, Han D, Zhang Y, Xu J, Lu J, et al. Activation of PPARgamma ameliorates pulmonary arterial hypertension via inducing heme oxygenase-1 and p21(WAF1): an in vivo study in rats. Life Sci 2014; 98: 39-43.

11 Wang G, Liu L, Zhang Y, Han D, Liu J, Xu J, et al. Activation of PPARgamma attenuates LPS-induced acute lung injury by inhibition of HMGB1-RAGE levels. Eur J Pharmacol 2014; 726: 27-32.

12 Liu J, Sakurai R, O'Roark EM, Kenyon NJ, Torday JS, Rehan VK. PPARgamma agonist rosiglitazone prevents perinatal nicotine exposure-induced asthma in rat offspring. Am J Physiol Lung Cell Mol Physiol 2011; 300: L710-7.

13 Park SY, Bae JU, Hong KW, Kim CD. HO-1 induced by cilostazol protects against TNF-alpha-associated cytotoxicity via a PPAR-gammadependent pathway in human endothelial cells. Korean J Physiol Pharmacol 2011; 15: 83-8.

14 Park SJ, Lee KS, Kim SR, Min KH, Choe YH, Moon H, et al. Peroxisome proliferator-activated receptor gamma agonist down-regulates IL17 expression in a murine model of allergic airway inflammation. J Immunol 2009; 183: 3259-67.

15 Jeffery PK. Remodeling and inflammation of bronchi in asthma and chronic obstructive pulmonary disease. Proc Am Thorac Soc 2004; 1 : 176-83.

16 Bao ZS, Hong L, Guan Y, Dong XW, Zheng HS, Tan GL, et al. Inhibition of airway inflammation, hyperresponsiveness and remodeling by soy isoflavone in a murine model of allergic asthma. Int Immunopharmacol 2011; 11: 899-906.

17 Brusselle GG, Maes T, Bracke KR. Eosinophils in the spotlight: eosinophilic airway inflammation in nonallergic asthma. Nat Med 2013; 19 : 977-9.

18 Takatsu K. Allergic inflammation and eosinophils: trials, tribulations and enigma of IL-5, eosinophils and asthma. Arerugi 2005; 54: 48-52.
19 Smith H. Asthma, inflammation, eosinophils and bronchial hyperresponsiveness. Clin Exp Allergy 1992; 22: 187-97.

20 Walsh GM, Sexton DW, Blaylock MG. Corticosteroids, eosinophils and bronchial epithelial cells: new insights into the resolution of inflammation in asthma. J Endocrinol 2003; 178: 37-43.

21 Johnson PR, Roth M, Tamm M, Hughes M, Ge Q, King G, et al. Airway smooth muscle cell proliferation is increased in asthma. Am J Respir Crit Care Med 2001; 164: 474-7.

22 Sakaguchi K, Morita I, Murota S. PPAR (peroxisome proliferator activated receptor), a factor that decides differentiation of adipocytes. Kokubyo Gakkai Zasshi 1997; 64: 458.

23 Krishnan A, Nair SA, Pillai MR. Biology of PPAR gamma in cancer: a critical review on existing lacunae. Curr Mol Med 2007; 7: 532-40.

24 Benayoun L, Letuve S, Druilhe A, Boczkowski J, Dombret MC, Mechighel $\mathrm{P}$, et al. Regulation of peroxisome proliferator-activated receptor gamma expression in human asthmatic airways: relationship with proliferation, apoptosis, and airway remodeling. Am J Respir Crit Care Med 2001; 164: 1487-94.

25 Woerly G, Honda K, Loyens M, Papin JP, Auwerx J, Staels B, et al. Peroxisome proliferator-activated receptors alpha and gamma downregulate allergic inflammation and eosinophil activation. J Exp Med 2003; 198: 411-21.

26 Honda K, Marquillies P, Capron M, Dombrowicz D. Peroxisome proliferator-activated receptor gamma is expressed in airways and inhibits features of airway remodeling in a mouse asthma model. J Allergy Clin Immunol 2004; 113: 882-8.

27 Grochot-Przeczek A, Dulak J, Jozkowicz A. Haem oxygenase-1: noncanonical roles in physiology and pathology. Clin Sci (Lond) 2012; 122: 93-103.

28 Liu X, Pachori AS, Ward CA, Davis JP, Gnecchi M, Kong D, et al. Heme oxygenase-1 (HO-1) inhibits postmyocardial infarct remodeling and restores ventricular function. FASEB J 2006; 20: 207-16.

29 Li M, Li Z, Sun X, Yang L, Fang P, Liu Y, et al. Heme oxygenase-1/ p21WAF1 mediates peroxisome proliferator-activated receptor-gamma signaling inhibition of proliferation of rat pulmonary artery smooth muscle cells. FEBS J 2010; 277: 1543-50.

30 Lee IT, Luo SF, Lee CW, Wang SW, Lin CC, Chang CC, et al. Overexpression of HO-1 protects against TNF-alpha-mediated airway inflammation by down-regulation of TNFR1-dependent oxidative stress. Am J Pathol 2009; 175: 519-32.

31 Kitada O, Kodama T, Kuribayashi K, Ihaku D, Fujita M, Matsuyama T, et al. Heme oxygenase-1 (HO-1) protein induction in a mouse model of asthma. Clin Exp Allergy 2001; 31: 1470-7.

32 Lee NH, Lee MY, Lee JA, Jung DY, Seo CS, Kim JH, et al. Antiasthmatic effect of Sanguisorba officinalis $L$ and potential role of heme oxygenase-1 in an ovalbumin-induced murine asthma model. Int J Mol Med 2010; 26: 201-8.

33 Lee MY, Seo CS, Ha H, Jung D, Lee H, Lee NH, et al. Protective effects of Ulmus davidiana var japonica against OVA-induced murine asthma model via upregulation of heme oxygenase-1. J Ethnopharmacol 2010; 130: 61-9.

34 Yang G, Nguyen X, Ou J, Rekulapelli P, Stevenson DK, Dennery PA. Unique effects of zinc protoporphyrin on HO-1 induction and apoptosis. Blood 2001; 97: 1306-13.

35 Fei D, Meng X, Zhao M, Kang K, Tan G, Pan S, et al. Enhanced induction of heme oxygenase- 1 suppresses thrombus formation and affects the protein C system in sepsis. Transl Res 2012; 159: 99109.

36 Wang QM, Du JL, Duan ZJ, Guo SB, Sun XY, Liu Z. Inhibiting heme oxygenase-1 attenuates rat liver fibrosis by removing iron accumulation. World J Gastroenterol 2013; 19: 2921-34. 
37 Kumar D, Bhaskaran M, Alagappan L, Tori D, Yadav I, Konkimalla S, et al. Heme oxygenase-1 modulates mesangial cell proliferation by $\mathrm{p} 21$ Waf1 upregulation. Ren Fail 2010; 32: 254-8.

38 Inguaggiato P, Gonzalez-Michaca L, Croatt AJ, Haggard JJ, Alam J, Nath KA. Cellular overexpression of heme oxygenase-1 up-regulates p21 and confers resistance to apoptosis. Kidney Int 2001; 60: 2181-91.

39 Gueders MM, Foidart JM, Noel A, Cataldo DD. Matrix metalloproteinases (MMPs) and tissue inhibitors of MMPs in the respiratory tract: potential implications in asthma and other lung diseases. Eur J Pharmacol 2006; 533: 133-44.

40 Oikonomidi S, Kostikas K, Tsilioni I, Tanou K, Gourgoulianis KI, Kiropoulos TS. Matrix metalloproteinases in respiratory diseases: from pathogenesis to potential clinical implications. Curr Med Chem 2009; 16: 1214-28.

41 Ohbayashi H. Matrix metalloproteinases in lung diseases. Curr Protein Pept Sci 2002; 3: 409-21.

42 Cauwe B, Van den Steen PE, Opdenakker G. The biochemical, biological, and pathological kaleidoscope of cell surface substrates processed by matrix metalloproteinases. Crit Rev Biochem Mol Biol 2007; 42: 113-85.

43 Shu T, Zeng B, Ren X, Li Y. HO-1 modified mesenchymal stem cells modulate MMPs/TIMPs system and adverse remodeling in infarcted myocardium. Tissue Cell 2010; 42: 217-22. 